\title{
Control of Airborne Microbes in a Poultry Setting Using Dioxy MP 14
}

http://dx.doi.org/10.1590/1516-635x170177-86

\section{-Author(s)}

Mbamalu O'

Uebel R'

Meki B"

Discipline of Pharmaceutics, School of Pharmacy, and

" Statistics Department, University of the Western Cape, Bellville, South Africa.

\section{Mail Address}

Corresponding author e-mail address Oluchi Mbamalu, School of Pharmacy, University of the Western Cape, Bellville 7535, South Africa. Phone: +27 21959 3229 /2190; Fax: +27865107002 E-mail: ombamalu@uwc.ac.za

\section{nKeywords}

Airborne microorganisms, biocide, chicken pen, chlorine dioxide, misting system.

\section{ABSTRACT}

In this study, Dioxy MP 14, a locally developed form of chlorine dioxide, was tested in a commercial chicken pen to determine its effectiveness as an airborne environmental sanitizing agent. The biocide was introduced via an overhead misting system with a variable dosing pump. The extent of airborne microbial control was determined with settle plates. Performance and mortality rate of the chickens in the experimental pen was compared to that in the control pen. Results show a decrease in airborne microbial load and a significantly higher egg productivity rate at a $5 \%$ level in the treated pen. However, no significant difference in mortality rates between the two pens was observed.

\section{INTRODUCTION}

Concern over microorganisms is mainly due to their relationship to morbidity and mortality (Mulder et al., 2009; Cohen ML, 2000). High microbial load associated with animal husbandry increases infection risk, resulting in considerable loss of infected animals (Ruano et al., 2001). In veterinary settings, the importance of hygiene and sanitation cannot be overemphasized; prevention and control of infectious disease outbreaks would ultimately result in healthier animals and improved productivity (Ruano et al., 2001; Wierup, 2000). Because disinfection of surface areas in veterinary settings may offer some limitation to significant microbial control, disinfection by aerosol mist may be employed (McKenzie et al., 1959). One advantage of this medium of dispersion is that particle size can be easily controlled. For example, the smaller the particle size, the longer the disinfectant will remain suspended in the atmosphere (a median diameter between 10 and $20 \mu \mathrm{m}$ has been found to be ideal), increasing its probability of coming in contact with airborne microbes (Burfoot et al., 1999; McKenzie et al., 1959).

It is pertinent though to mention that determining the efficacy of a disinfectant under controlled conditions may not necessarily be indicative of its performance in actual use. To be considered effective, aerosol mists containing disinfectants must show activity under conditions obtained in day-to-day settings, which may not permit disinfection under optimum conditions of temperature and humidity (McKenzie et al., 1959). Disconcerting though this may sound, it emphasizes how difficult it is to guarantee effective disinfection in all circumstances (Lloyd-Evans et al., 1986; McKenzie et al., 1959).

The current study was carried out in a chicken farm to test the efficacy of a locally manufactured biocide, Dioxy MP 14. This chemical is a stabilized aqueous solution of chlorine dioxide, whose effects in air and surface decontamination have been investigated in a number of settings (Hsu et al., 2012; Callahan et al., 2010; Lin et al., 2007; Huang et al., 2006; Sy et al., 2005). 
A few recent studies including Hsu et al. (2012) and Lin et al. (2007) have looked at the use of chlorine dioxide mist in airborne microbial control; however, these were in clinical settings.

To the best of our knowledge, the current study is the first of its kind to investigate the efficacy of aqueous chlorine dioxide in mist form for air disinfection. This investigation was based on an overall objective of determining an optimum concentration of the biocide that not only effectively minimizes bacterial concentration but also does not negatively affect chick performance. Thus, it was important to assess the efficacy of this biocide under normal dayto-day working conditions; hence, no evacuation was necessary, as the exposure level was quite low. Staff at the poultry farm were free to go about their business while the study was being conducted. The misting pump delivered the biocide in so fine a form that even though the mist was visible, no wetting occurred, thus ensuring minimum disruption, an advantage over spraying just ordinary liquid.

The experimental setup is detailed in the next section, thereafter, the overall objective mentioned earlier is split and analysed as two primary objectives in Statistical Analyses. Here, the preferred methods of respective analyses are outlined. Analysis of each of the primary objectives will constitute a subsection of Statistical Analyses, detailing the respective hypotheses underlying the investigation of each objective. The data, analyses and discussions of the results of each investigation are also presented here. An overall conclusion summarizing the two discussions and thus the overall objective stated above is given in Conclusion and Recommendations.

\section{MATERIALS AND METHODS \\ MATERIALS}

Dioxy MP 14 a stabilized aqueous chlorine dioxide solution of approx. 2000 ppm (Vivré Plant Health, Paarl, South Africa), nutrient agar (Merck, South Africa), potato dextrose agar (Merck, South Africa), sterile agar plates ( $B$ \& M Scientific, South Africa).

\section{METHODS}

The study design was a result of detailed discussions between the manufacturers of the dry mist system / Dioxy MP 14 and an experienced poultry farmer who shared the goal of improving yield via control of microbial contamination.

As a result, this study investigates the effects, if any, of applying Dioxy MP 14, an aqueous solution of chlorine dioxide, in poultry husbandry. For this purpose, two objectives are identified and investigated: first, the optimal biocide concentration of Dioxy MP 14 is determined based on how effectively it minimizes bacterial contamination and secondly, the effects of continuous application of the optimum biocide are determined by analysing chick performance over the 8-month study period. The combination of these two objectives results in determining an optimum concentration of the biocide that effectively minimizes bacterial concentration and does not negatively affect chick performance. The two objectives are discussed at length in Statistical Analyses.

\section{Selection of optimum biocide concentration}

The aqueous biocide solution was released into the experimental pen by a dry mist system at four different concentrations. The different concentrations were sprayed on different days. Chlorine dioxide is a very reactive compound and quickly disintegrates on exposure (Dunn \& Simon, 1992; Gordon, 2001). Nevertheless, a period of at least 3 days was observed between subsequent biocide dosings in order to ensure there was no interacting effect from the previous dose. Pen $A$ received the biocide while pen $B$ (which served as the control) was not equipped with a misting system and therefore not treated (Fig 1 and 2). Settle plates containing nutrient agar and potato dextrose agar
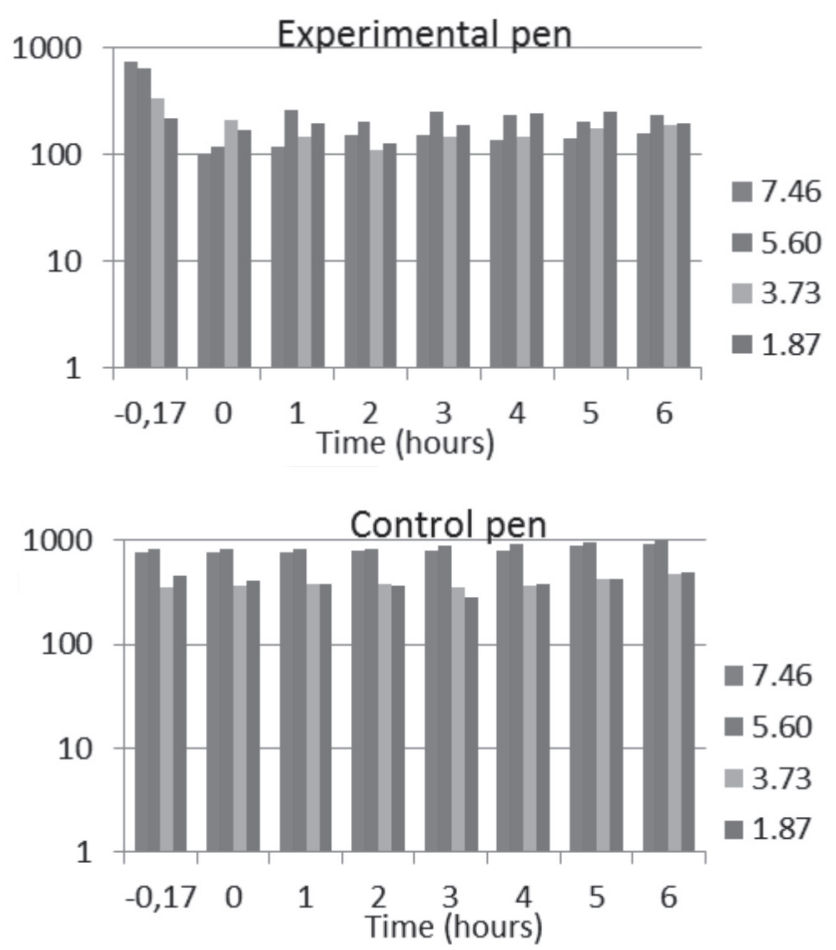

Figure 1 - Plot of bacterial contamination in the experimental and control pens on application of different biocide concentrations. Data are shown as log CFUs versus time. 


\section{Control of Airborne Microbes in a Poultry Setting Using Dioxy MP 14}

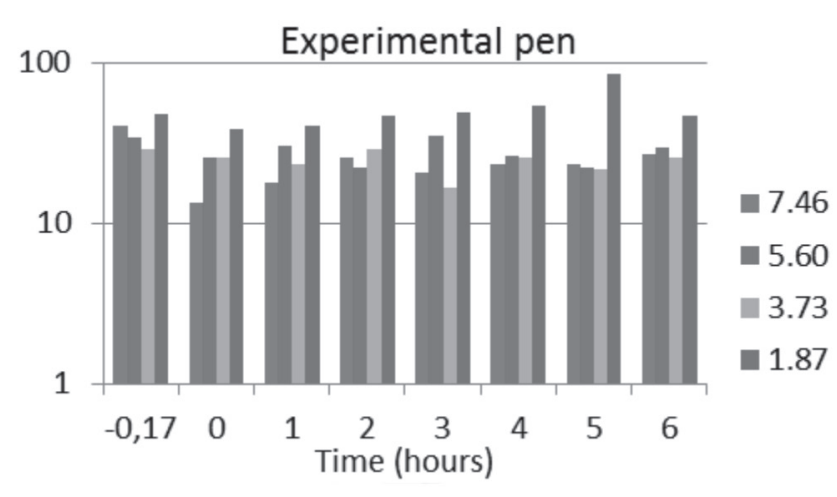

each month were calculated. Production performance and mortality over the various months (in percentage) were calculated as:

$$
\text { Production }(\%)=(\text { trays } * 30 * 100) / \text { c.stock }
$$

where "trays" refers to the number of trays of eggs produced by the chickens (each tray contained 30 eggs) and "c.stock" refers to current stock (the population of the chickens at the time of egg collection). 100\% performance was defined as the percentage value obtained if the number of eggs laid equalled the number of chickens in the pen at the time of egg collection.

Mortality $(\%)=$ total number of chicken deaths for the month * $100 /$ o.stock

where "o.stock" refers to the number of chickens at the beginning of the month.

Other aspects of the experiment that should be mentioned include details on how the experimental pen was fitted with the necessary equipment and how data were collected. These are discussed at length below.

\section{Pen fitting for study purposes}

The experimental and control pens measured approximately $25 \mathrm{~m}$ by $13 \mathrm{~m}$ each. The experimental pen was rigged with pipes, pressure nozzles, and supplied with a dosing pump, all supplied and installed by Magic Mist, South Africa. The pipes (fitted with the pressure nozzles from which the mist was released) hanged $2.8 \mathrm{~m}$ above the floor of the chicken house. The nozzles had an orifice diameter of $0.2 \mathrm{~mm}$ and were made of cleanable brass with a removable stainless impeller plate which could be taken apart for cleaning purposes. A distance of 1 metre was maintained between nozzles. Spray projection ranged from 1.5 to 3 metres depending on a number of factors, such as pressure, humidity, orientation, and air movement.

The whole fixture in the experimental pen had a total of 73 nozzles and at a pressure of 60 Bar, pumped 6.13 liters of water per minute (flow rate at 60 Bars $=84 \mathrm{~mL}$ minute from each nozzle). Chickens were housed in two horizontal rows of cages adjacent to each other and placed about $2 \mathrm{~m}$ from another horizontal row of cages. The height of the lowest cage above the ground was $80 \mathrm{~cm}$. Each cage measured $46 \mathrm{~cm} \times 46 \mathrm{~cm} \times 46$ $\mathrm{cm}$ and housed four chickens.

The pens were ventilated through wire mesh openings between the top of the wall and the roof. These were present on opposite walls of the pen, allowing cross ventilation. 


\section{Air sampling}

Air sampling was carried out with settle plates exposed on top of the metal cages housing the birds. The top of the cages were about $1.8 \mathrm{~m}$ above the ground and about $1 \mathrm{~m}$ from the overhead pipes that supplied the biocide in solution. A piece of rigid plastic sheet (A4 paper size) was wiped with a solution of $70 \%$ alcohol (to remove any contaminating microbes suspected to be present) and placed on top of the topmost cage, at the furthest possible distance from the nozzles. The settle plates, clearly marked and labelled, were placed on it with a gloved hand. The cover was removed and placed face down on the sheet to ensure that no extra microbes were introduced through it.

For each testing session, three settle plates containing nutrient agar (for assessment of bacterial contamination) and another three containing potato dextrose agar (for assessment of yeast and mould contamination) were exposed. At the end of the exposure period (5 minutes), the cover was replaced. The plates were neatly stacked and secured in a plastic bag that was put into an insulated container for transportation to the microbiology laboratory.

\section{STATISTICAL ANALYSES}

All analyses of the data were carried out using the statistical programming software $R$ version 3.1.0 for Windows. To maintain the reader's focus, a two stage multi-layered analysis approach is proposed here. The overall goals of this investigation are built around selected objectives. Each objective presents a particular test case(s) based on appropriate and detailed hypotheses. The first stage of the analysis was concerned with understanding the biocide effects on bacterial contamination in the experimental pen. The second stage investigated the biocide effects on chicken performance, where said performance is defined as egg production and chicken mortality concurrently. As mentioned earlier, these two objectives summarize an optimal biocide concentration that, while not negatively impairing chick performance, is still able to significantly minimize bacterial contamination.

\section{Biocide effects on bacterial levels}

The main goal of determining biocide effects on bacterial levels is detailed in three objectives given here. Each objective presents certain hypotheses to be tested. Respective methodologies of how each objective is analysed are also specified. The data to be analysed is described and the empirical results are given here also.

\section{Objective 1}

Here, bacterial contaminations were recorded and compared between pens $A$ and $B, 5$ minutes before and 5 minutes after application of the Dioxy MP 14 biocide. The biocide was sprayed continuously for 10 minutes. Four test cases were constructed and their respective hypotheses are given in the table below.

Table 1 - Objective 1 Tests and Hypotheses- Bacterial contamination between pens $A$ and $B$

\begin{tabular}{lll}
\hline & Null Hypothesis $\left(\mathrm{H}_{0}\right)$ & Alternative Hypothesis $\left(\mathrm{H}_{\mathrm{a}}\right)$ \\
\hline Test 1 & $\begin{array}{l}\text { Pen A } 5 \text { mins before = Pen B } \\
5 \text { mins before }\end{array}$ & $\begin{array}{l}\text { Pen A } 5 \text { mins before } \neq \text { Pen B } 5 \\
\text { mins before }\end{array}$ \\
\hline Test 2 & $\begin{array}{l}\text { Pen A } 5 \text { mins after = Pen B } \\
\text { 5mins after }\end{array}$ & $\begin{array}{l}\text { Pen A } 5 \text { mins after }<\text { Pen B } 5 \\
\text { mins after }\end{array}$ \\
\hline Test 3 & $\begin{array}{l}\text { Pen B } 5 \text { mins before = Pen B } \\
\text { 5mins after }\end{array}$ & $\begin{array}{l}\text { Pen B } 5 \text { mins before } \neq \text { Pen B } 5 \\
\text { mins after }\end{array}$ \\
\hline Test 4 & $\begin{array}{l}\text { Pen A } 5 \text { mins before = Pen A } \\
5 \text { mins after }\end{array}$ & $\begin{array}{l}\text { Pen A } 5 \text { mins before }>\text { Pen A } 5 \\
\text { mins after }\end{array}$ \\
\hline
\end{tabular}

Notes: Data were compared 5 minutes before and 5 minutes after application of the biocide.

Though expected, the first test suggested above provided statistical evidence that showed that bacterial contamination recorded in both the experimental $(A)$ and control (B) pens before carrying out the experiment were comparatively about the same. The remaining three tests, on the other hand, attempted to show that immediately after applying the biocide, bacterial contamination in the experimental pen was statistically significantly lower than that observed in the control pen. This, in turn, would provide preliminary evidence of the effectiveness of the biocide, Dioxy MP 14, against bacterial contamination as observed within each six-hour testing period.

No assumption about normality of the bacterial contamination recordings was made. Thus, the hypotheses given in Table 1 were tested using the Wilcoxon-Mann-Whitney test defined as,

$$
W=\min \left(U_{A^{\prime}} U_{B}\right)
$$

Where $W$ is the test statistic and $U_{A}\left(U_{B}\right)$ is total number of times (per month) pen $A(B)$ produced more egg trays compared to pen $B(A)$. The statistic is meaningful if

$$
U_{A}+U_{B}=n_{A} n_{B}
$$

where both $n_{A}$ and $n_{B}$ denote the number of egg trays produced in pens $A$ and $B$ respectively. If $n_{A} n_{B}>$ 20 (this is true in this research, see Results section), then the $p$-value is calculated based on the normal approximation of the test statistic with parameters, $m_{u}$ and $s_{U}$, defined as follows: 
$\mu_{U}=\frac{n_{A} n_{B}}{2}$ and $\sigma_{U}=\sqrt{\frac{n_{A} n_{B}(N+1)}{12}}$

where the total sample size is defined as $N=n_{A}+n_{B}$.

\section{Selection of optimum biocide concentration}

\section{Objective 2}

Four biocide concentrations of 7.46 ppm, 5.60 ppm, 3.73 ppm and 1.87 ppm were applied to pen A, and samples taken every hour for six hours. The effectiveness of each dose was measured in terms of bacterial contamination recorded every hour after spraying the pen. What is of interest here is to determine whether the effectiveness of the biocide was statistically equivalent across all four doses in the sampling period. In other words, a test on the four biocide doses is conducted on the following hypotheses;

$H_{0}$ : On average, the four biocide concentrations result in equal reductions of bacterial contaminations .

$H_{A}$ : At least one biocide concentration's effectiveness on bacterial contamination is markedly different.

Rejection of the alternative hypothesis would suggest that the effectiveness of the Dioxy MP 14 biocide on combating bacterial contamination is relatively constant regardless of the dosage used. On the other hand, rejecting the null hypothesis would suggest that different biocide concentrations have significantly different levels of effectiveness when combating bacterial contamination.

The first three doses resulted in 24 observations each and the 1.87ppm dose gave only sixteen observations. Missing data due to chick disruption and / or other reasons were ignored. No assumptions about normality of the data were made and as a result, the stated hypotheses under the second objective were investigated using the Kruskal-Wallis analysis of variance test.

\section{Objective 3}

Favouring the alternative hypothesis in Objective 2 above suggests the possibility of an optimal biocide concentration. This optimal concentration is found by regressing all bacterial contamination levels collected over the sampling period on the four selected biocide concentrations, and then varying the biocide concentrations and observing the resulting levels of bacterial contamination. The concentration producing the lowest bacterial levels is identified as the optimal dose. The resulting equation will be of the form:

$$
\mathrm{BL}=\alpha+\beta \star B C+\text { error (4) }
$$

Where $\alpha$ and $\beta$ are parameters to be estimated and the inherent margin of error is simply given as "error". Equation (4) is estimated using the method of least squares based on log-transformed data. The abbreviations "BL" and "BC" denote Bacterial level and Biocide concentration respectively.

\section{Data Description}

Recordings of bacterial contaminations were collected from both the experimental and control pens five minutes before and five minutes after applying a dose, and every hour henceforth for six hours. The data comprises 24 logged CFUs. Any missing data is omitted.

\section{Empirical Results and Discussion}

The initial part of the analyses involves a report on the results of the hypotheses given under the first objective (see the Methodology section). These results are summarized in Table 2.

Table 2 - Objective 1 Tests Results - Bacterial contamination between pens $A$ and $B$

\begin{tabular}{llll}
\hline & \multicolumn{1}{c}{$\begin{array}{c}\text { Test Statistic } \\
(\mathrm{p} \text {-value })\end{array}$} & $\begin{array}{c}\text { Null Hypothesis } \\
\left(\mathrm{H}_{0}\right)\end{array}$ & $\begin{array}{c}\text { Alternative Hypothesis } \\
\left(\mathrm{H}_{\mathrm{a}}\right)\end{array}$ \\
\hline Test 1 & $W=38.5(0.158)$ & Do not reject & Reject \\
\hline Test 2 & $W=0\left(0.000^{* * *}\right)$ & Reject & Do not reject \\
\hline Test 3 & $W=54.5(1)$ & Do not reject & Reject \\
\hline Test 4 & $W=2\left(0.000^{* * *}\right)$ & Reject & Do not reject \\
\hline
\end{tabular}

Notes: Please refer to Table 1 for descriptions of the respective hypotheses in each test case.

Objective 1 is investigated using the Wilcoxon-Mann-Whitney test. "W" denotes the test's test statistic. Significance levels at $10 \%, 5 \%$ and $1 \%$ are denoted by *,**,*** respectively.

According to Table 2, the null hypothesis for the first test case cannot be rejected at a $5 \%$ significance level. These findings suggest that the levels of bacterial contaminations between the two pens as recorded five minutes before each six hour experiment window are statistically equivalent. However, results for Test 2 show that bacterial levels for pen A five minutes after the biocide was sprayed were significantly lower than those recorded for pen B at a 5\% level. Moreover, Test 3 reveals that the bacterial contamination levels in pen $B$ remained relatively constant over the sampling period while those of pen A showed significant decrease (see Table $1 \mathrm{~b}$, Test 4 results) after applying the biocide. These results were also concluded at a $5 \%$ level of significance, respectively.

The results given in Table 2 simply show that indeed the Dioxy MP 14 biocide significantly decreased bacterial contamination in the experimental pen. 


\section{Control of Airborne Microbes in a Poultry Setting Using Dioxy MP 14}

However, since different doses of the biocide were administered during the 8-month research period, it is not possible to determine at this stage whether the results observed thus far can be equally attributed to all four doses. This issue is presented under the second objective (see objective 2 in the Statistical analyses section) and the Kruskal-Wallis test gives a Chi-squared test statistic of 28.518 with 3 degrees of freedom and a $p$-value $=0.000$. These results reject the null hypothesis at a $5 \%$ level of significance in favour of the alternative that the respective effectiveness of each of the four concentrations of the biocide differs significantly from the next over the sampling period.

What the results have shown thus far is that it is possible to determine an optimal concentration level. As outlined in the third objective above (see objective 2 in the Statistical analyses section), this is achieved by first regressing bacterial contamination levels on the four selected biocide concentrations. This yields the following regression equation:

$$
B L={ }_{[45.62]}^{2.30}-0.10 * B C+\text { error }
$$

Since both bacterial levels and biocide concentrations are analysed as log CFUs, then according to the regression (5) above, a 1\% increase in biocide concentration will result in $0.1 \%$ decrease in bacterial contamination. Varying the dependent variable over the four doses reveals that the optimal concentration level is $7.46 \mathrm{ppm}$ with the lowest CFU count of 165 over the sampling period. The t-values (given in brackets) show that the biocide concentration is not statistically significant and, according to the R-squared value, equation (5) can only account for $2.9 \%$ of the variation in the response data. Since the experiment was conducted on an open system, environmental factors such as temperature, humidity, wind speed and direction could have significantly influenced contamination levels. In turn, this could have led to the low calculated statistics for equation (5) despite observation and intuition supporting the notion of microbial control by biocide dosage. Nevertheless, future studies could consider other models besides the one presented in equation (5).

\section{Biocide effects on chick performance}

This part of the study maintains that after selecting the optimum biocide concentration that minimizes bacterial concentration levels, it should be investigated if this dose has any effects on chick performance. This is determined by statistically comparing chick mortality and egg productivity between pen A (treated with the biocide) and pen $B$ (the control pen). The analyses cover an 8-month period over which performance and mortality data were collected.

\section{Objective 4}

Here, the investigation is designed around the following arguments:

1. If the biocide does indeed significantly reduce bacterial contamination in pen $A$, then chick health is expected to be improved and as such, chick mortality is expected to be diminished. To this effect, is can be posited that the control pen, B, should exhibit a significantly higher mortality rate over the sampling period compared to pen A. This argument is investigated by testing the hypotheses given in table 2a corresponding to Test 1 .

2. In addition, if the biocide reduces chick mortality then it is intuitive to expect that egg productivity in pen A should be significantly greater than that of pen B. This assertion is investigated by testing the hypotheses given in Table 3 corresponding to Test 2 .

Table 3 - Objective 4 Tests and Hypotheses - Biocide effects on chick performance

\begin{tabular}{lcc}
\hline & Null Hypothesis $\left(H_{0}\right)$ & Alternative Hypothesis $\left(H_{A}\right)$ \\
\hline Test 1 & $\mu_{A}^{\text {mortality }}=\mu_{B}^{\text {mortality }}$ & $\mu_{A}^{\text {mortality }}>\mu_{B}^{\text {mortality }}$ \\
\hline Test 2 & $\mu_{A}^{\text {productivity }}=\mu_{B}^{\text {productivity }}$ & $\mu_{A}^{\text {productivity }}>\mu_{B}^{\text {productivity }}$ \\
\hline Notes: $\mu_{A}^{\text {mortality }}$ and $\mu_{B}^{\text {mortality }}$ denote average mortality rates for pens A and B \\
respectively. $\mu_{A}^{\text {productivity }}$ and $\mu_{B}^{\text {productivity }}$ denote average productivity rates for \\
pens A and B respectively.
\end{tabular}

We are aware that the arguments presented in Table 3 above might be overly simplified. Indeed, it is possible that though the biocide may curb chick mortality, this may not necessarily imply improved egg productivity. The reverse may also not be necessarily true. As such, the ensuing analyses adhere only to the hypotheses presented above. Any possible counter arguments to findings herein are left to future researchers to ponder.

The hypotheses given in Table 3 above are investigated using basic two-sample hypothesis tests based on the Normal distribution. The normality assumption is simply based on the large sample sizes recorded for both productivity and chick mortality. The reader is referred to any introductory statistics text for further reading on Normal distribution based twosample hypothesis testing. 


\section{Data Description}

At the beginning of the study, the chickens were just over 30 weeks old and past their peak productivity according to the commercial performance chart. As a result, productivity from the two pens was on a steady decline during the sampling period. The data comprised 238 observations: 13,279 egg trays recorded for pen A and12,870 trays for pen B over the sampling period. At the beginning of the experiment, 2132 chickens were housed in Pen A and 2171 chickens were housed in Pen B. At the end of the study, 1826 birds were recorded for Pen $A$ and 1824 chickens were noted for Pen B.

\section{Empirical Results and Discussion}

Raw data are analysed and the results are given in two parts. The first part summarizes chick performances in Table 4 below.

Table 4 - Summary Statistics for Chicken Performance between Pens $A$ and $B$

\begin{tabular}{lcccc}
\hline Pen & A & B & A & B \\
\hline & \multicolumn{2}{c}{ Mortality } & Egg productivity \\
\hline Mean & 1.29 & 1.46 & 56 & 54 \\
\hline Median & 1 & 1 & 55 & 54 \\
\hline Mode & 1 & 1 & 50 & 59 \\
\hline Standard deviation & 0.98 & 1.40 & 6 & 6 \\
\hline Minimum & 0 & 0 & 46 & 43 \\
\hline Maximum & 6 & 10 & 68 & 73 \\
\hline Sum & 306 & 347 & 13279 & 12870 \\
\hline Count & 238 & 238 & 238 & 238 \\
\hline
\end{tabular}

Notes: "Egg productivity" is measured by number of egg trays produced daily.

According to Table 4 given above, on average, one chicken was lost daily from both pens $A$ and $B$, with pen $B$ losing the most number (10) of chickens in one day compared to pen $A$ which only lost a maximum of 6 birds. All-in-all, pen B recorded 347 deaths while pen A observed 306 deaths over the sampling period.

Pen A recorded an average of 56 egg trays over the sampling period, while pen $B$ recorded 54 trays. Table $2 \mathrm{~b}$ suggests that Pen $\mathrm{B}$ had a slightly wider dispersion with respect to egg production. This is given by a range of $73-43=30$ egg trays from pen $B$ and a range of 68$42=22$ trays from pen $A$. Even though pen $B$ frequently produced 59 trays, a higher count than 50 trays on most days recorded for pen $A$, it is possible that on many of the remaining occasions, pen $B$ produced significantly fewer egg trays by comparison. The result was a lower total count of 12870 trays recorded for pen $B$ compared to 13279 trays produced by chickens housed in pen $A$.

The second part of the investigation of the fourth objective seeks to determine if the optimum biocide concentration had any effect on chick performance. This is achieved by comparing productivity and chick mortality data between the two pens using twosample tests to investigate the hypotheses given in Table 3. The results are given in Table 5 .

Table 5 - Objective 4 Tests Results - Biocide effects on chick performance

\begin{tabular}{cccc}
\hline & $\begin{array}{c}\text { Test Statistic } \\
(\mathrm{p} \text {-value })\end{array}$ & Null Hypothesis $\left(H_{0}\right)$ & Alternative Hypothesis $\left(H_{A}\right)$ \\
\hline Test 1 & $\mathrm{Z}=1.54$ & Do not reject & Reject \\
\hline Test 2 & $\mathrm{Z}=3.64^{* * *}$ & Reject & Do not reject \\
\hline
\end{tabular}

Notes: Objective 4 is investigated using the Z-test for two populations. "Z" denotes the Normal distribution test statistic. Significance levels at 10\%, 5\% and $1 \%$ are denoted by ${ }^{*},{ }^{*},{ }^{* * *}$ respectively.

According to table 5 above, the null hypothesis in the first test case is not rejected at $5 \%$ significance level. This suggests that the mortality rate for the control pen (B) is not greater than that of pen $A$ where the biocide was applied. This may imply that the biocide did not significantly affect chick mortality as was posited earlier. However, the null hypothesis for the second test case is rejected at a $5 \%$ level of significance. This result points to the possibility that, on average, pen $A$ did indeed record significantly greater egg production compared to pen B. It may be suggested that instead of reducing the mortality rate, the effect of the biocide could have been in reducing particular bacteria that stunt egg productivity instead. As a result, with mortality rate unchanged, average egg productivity was significantly increased. This is just one possible explanation of this result, we do concede to the possibility of many other, potentially more viable, explanations that could be given in later studies of similar nature.

\section{CONCLUSION AND RECOMMENDATIONS}

\section{Conclusion}

This study was conducted to assess the efficacy of Dioxy MP 14 in the control of airborne contaminants in a poultry house, and by inference, its effect on performance (measured by productivity and mortality). There were two sections to the study: one involved the selection of optimum biocide concentration that significantly reduced bacterial concentrations, and the 
second consisted of assessing the effects of continuous application of the determined optimum biocide concentration with respect to chick performance . At the end of the study, we came to the following conclusions:

Dioxy MP 14 at a maximum chlorine dioxide concentration of 7.46 ppm successfully and significantly reduced bacterial contamination levels in the experimental pen. Continued use of the biocide over an 8-month period proved to have no observable adverse effects on the health of the fowl. Moreover, though there was no significant reduction of the mortality rate at a $5 \%$ significance level, egg production was significantly high over the observed period.

This study was only exploratory; the concentration found to reduce microbial contamination in another contaminated setting or even in a different poultry house could vary from that obtained in the study. Such values may in effect depend on the original contamination (before disinfection) in the said setting and the influence of the surrounding environment among other factors, and thus may warrant further investigation.

\section{Recommendations}

This study was only exploratory; it is not difficult to note that it is possible to obtain different optimum biocide concentrations by merely varying some factors in a similar experiment. As such, we concede to the fact that the results presented here are not "set in stone".

Nonetheless, this experiment has made it possible for us to recommend that the effect of a longer period of constant dosing of the biocide, in a controlled setting, be investigated. In addition, the effect of environmental factors such as temperature, humidity and wind speed/direction could be more strictly controlled for as it is easy for the experiment, and hence the results, to be biased by these factors. In so doing, it may then be easier to explain the variation in, for example, bacterial contamination levels observed from samples taken within a given interval, as well as the difference in productivity observed in both pens.

\section{Funding sources}

This study was partly funded by Vivré Plant Health and Magic Mist, South Africa.

\section{ACKNOWLEDGEMENTS}

The authors wish to acknowledge the management and staff of Bellevue Farm, Paarl, for the use of their facilities.

\section{REFERENCES}

Burfoot D, Hall K, Brown K, Xu Y. Fogging for the disinfection of food processing factories and equipment. Trends in Food Science and Technology 1999;10:205-210.

Callahan KL, Beck NK, Duffield EA, Shin G, Meschke JS. Inactivation of methicillin-resistant Staphylococcus aureus (MRSA) and vancomycinresistant Enterococcus faecium (VRE) on various environmental surfaces by mist application of a stabilized chlorine dioxide and quaternary ammonium compound-based disinfectant. Journal of Occupational and Environmental Hygiene 2010;7:529-534.

Canter D. Addressing residual risk issues at anthrax cleanups: how clean is safe? Journal of Toxicology and Environmental Health, Part A 2005;68:1017-1032.

Canter DA, Gunning D, Rodgers P, O'Connor L, Traunero C, Kempter CJ. Remediation of Bacillus anthracis contamination in the U.S. Department of Justice mail facility. Biosecurity and Bioterrorism 2005;3:119-127.

Cohen ML. Changing patterns of infectious disease. Nature 2000;406:762767.

Davies A, Pottage T, Bennett A, Walker J. Gaseous and air decontamination technologies for Clostridium difficile in the healthcare environment. Journal of Hospital Infection 2011;77:199-203.

Dawson MW, Brown TJ. The effect of chlorine and chlorine dioxide on pathogenic free living amoebae (PFLA) in simulated natural conditions: the presence of bacteria and organic matter. New Zealand Journal of Marine and Freshwater Research 1987;21:117-123.

Den Boer JW, Yzerman EPF, Schellekens J, Lettinga KD, Boshuizen HC, Van Steenbergen JE, Bosman A, Van den Hof S, Van Vliet HA, Peeters MF. A large outbreak of legionnaires' disease at a flower show, the Netherlands, 1999. Emerging Infectious Diseases 2002;8:37-43.

Douwes J, Thorne P, Pearce N, Heederik D. Bioaerosol health effects and exposure assessment: progress and prospects. The Annals of Occupational Hygiene, 2003;47:187-200.

Douwes J, Wouters I, Dubbeld H, van Zwieten L, Steerenberg P, Doekes G, Heederik D. Upper airway inflammation assessed by nasal lavage in compost workers: a relation with bio-aerosol exposure. American Journal of Industrial Medicine 2000;37:459-468.

Dunn RC, Simon JD. Excited-state photoreactions of chlorine dioxide in water. Journal of the American Chemical Society 1992;114:4856-4860.

Gordon G. Is all chlorine dioxide created equal? Journal of the American Water Works Association 2001;93:163-174.

Hota B. Contamination, disinfection, and cross-colonization: Are hospital surfaces reservoirs for nosocomial infection? Healthcare Epidemiology 2004;39:1182-1189.

Huang T-S, Xu C, Walker K, West P, Zhang S, Weese J. Decontamination efficacy of combined chlorine dioxide with ultrasonication on apples and lettuce. Journal of Food Science 2006;71:M134-M139.

Hsu CS, Lu MC, Huang DJ. Application of chlorine dioxide for disinfection of student health centers. Environmental Monitoring and Assessment 2012;184(2):741-7477.

Isomoto H, Urata M, Kawazoe K, Mastuda J, Nishi Y, Wada A, Ohnita K, Hirakata Y, Matsuo N, Inoue K, Hirayama T, Kamihira S, Kohno S. Endoscope disinfection using chlorine dioxide in an automated washerdisinfector. Journal of Hospital Infection 2006; 63:298-305.

Kepinski J, Trzeszczynski J. Absorption equilibrium of chlorine dioxide: Solubility in water, carbon tetrachloride, sulfuric, and acetic acid solutions. Roczniki Chemii (Chemical Abstracts) 1964;38:201-211. 
Lin KS, Hsieh MJ, JerLiou M, Lee SL, Lai C-K. Disinfection effect of chlorine dioxide on air quality control in Armed Forces General Hospital of Taiwan. Nature and Science 2007; 5(4):94-99.

Lloyd-Evans N, Springthorpe VS, Sattar SA. Chemical disinfection of human rotavirus-contaminated inanimate surfaces. The Journal of Hygiene 1986;97:163-173.

McKenzie DA, Lambert J, Getty J. Studies on aerosol disinfection of poultry premises. Journal of Applied Bacteriology 1959;22:258-263.

Mulder N, Rabiu H, Jamieson G, Vuppu V. Comparative analysis of microbial genomes to study unique and expanded gene families in Mycobacterium tuberculosis. Infection, Genetics and Evolution 2009;9:314-321.

Polanczyk RA, Zanúncio JC, Alves SB. Relationship between chemical properties of the soil and the occurrence of Bacillus thuringiensis. Ciência Rural 2009;39:1-5.

Ruano M, El-Attrache J, Villegas P. Efficacy comparisons of disinfectants used by the commercial poultry industry. Avian Diseases 2001;45:972977.
Sy KV, McWatters KH, Beuchat LR. Efficacy of gaseous chlorine dioxide as a sanitizer for killing salmonella, yeasts, and molds on blueberries, strawberries, and raspberries. Journal of Food Protection 2005;68:11651175 .

Vandekinderen I, Devlieghere F, Van Camp J, Kerkaert B, Cucu T, Ragaert $P$, De Bruyne J, De Meulenaer B. Effects of food composition on the inactivation of foodborne microorganisms by chlorine dioxide. International Journal of Food Microbiology 2009;131:138-144.

Van Lier JB, Huibers FP. From unplanned to planned agricultural use: making an asset out of wastewater. Irrigation and Drainage Systems 2010; 24:143-152.

Wierup M. The control of microbial diseases in animals: alternatives to the use of antibiotics. International Journal of Antimicrobial Agents 2000;14:315-319 
